\title{
ANALISIS PERBANDINGAN ANTARA PENDAPATAN DRIVER GOJEK FULLTIME DAN UPAH MINIMUM REGIONAL KOTA SURABAYA
}

\author{
Muhammad Riza Falefi ${ }^{1}$, Bambang Dwi Waryanto ${ }^{2}$ \\ Universitas PGRI Adi Buana Surabaya \\ falefialriza@gmail.com
}

\begin{abstract}
ABSTRAK
Penelitian ini bertujuan unutk mengetahui penghasilan driver gojek fulltime berada di atas atau di bawah UMR kota Surabaya. UMR yang berlaku di kota Surabaya sebesar Rp 4.200.479,00 berdasarkan keputusan Gubernur Jatim, Khofifah Indar Parawansa nomor 188/568/KPTS/013/2019 tanggal 20 November 2019 tentang Upah Minimum Regional provinsi Jawa Timur Tahun 2020. Pengumpulan data dilakukan dengan teknik observasi, wawancara, dan dokumentasi. Penelitian ini menggunakan data primer yang berupa hasil wawancara dan observasi. Data sekunder yang berupa sejarah, visi \& misi, dan peraturan-peraturan yang ada di webside resmi PT Gojek Indonesia. Metode analisis data yaitu deskriptif komparatif. Wawancara diberikan kepada 50 driver gojek fulltime. hasil penelitian menunjukkan pendapatan bersih yang diterima oleh driver gojek fulltime sebanyak $75 \%$ pendapatannya berada di atas UMR kota Surabaya dan $25 \%$ pendapatannya berada di bawah UMR kota Surabaya.
\end{abstract}

Kata kunci: pendapatan, UMR, deskriptif, komparatif, gojek

\begin{abstract}
The purpose of this study is to determine the income of fulltime goat drivers above or below the UMR of Surabaya. The UMR in force in the city of Surabaya is $R p$ 4,200,479.00 based on the East Java Governor's decision, Khofifah Indar Parawansa number 188/568 / KPTS / 013/2019 dated 20 November 2019 concerning Regency / City Mininum Wages in East Java in 2020. Data collection using techniques observation, interview and documentation. This study uses primary data in the form of interviews and observations. Secondary data in the form of history, vision \& mission, and regulations on the official website of PT Gojek Indonesia. The data analysis method is comparative descriptive. Interviews were given to 50 full-time taxi drivers. The results showed that $75 \%$ of the income received by the full-time gojek drivers was above the Surabaya UMR and $25 \%$ of the revenue was below the Surabaya UMR.
\end{abstract}

Keywords: income, UMR, descriptive, comparative, object 


\section{PENDAHULUAN}

Dalam dunia ketenagakerjaan yang perkembangannya sangat pesat saat ini, para pelaku pembisnis di Indonesia sangat sering mengalami kendala mengenai besarnya upah dan berapa kenaikan di setiap tahunnya, yang harus dibayarkan kepada karyawan yang membantu bisnis mereka. Menurut Tri Siwi Agustina (2015) Upah ialah pemberian yang diberikan perusahaan selaku balas jasa atas hasil aktivitas yang diperoleh oleh tenaga kerja. Dalam penetapan Upah Minimum Regional (UMR), setiap tahun pemerintah melakukan pengkajian UMR setiap tahun. UMR yang ditetapkan oleh pemerintah, berlaku secara umum dan penetapan dari upah minimum tersebut akan berbeda dengan daerah yang lain. Dunia transportasi juga tidak terlepas dari permasalahan tentang besarnya nilai upah. Transportasi sangat penting dalam menunjang pertumbuhan ekonomi Indonesia. Angkutan umum memiliki peran penting dalam mendorong pembangunan negara, yaitu sebagai pendorong serta beguna sebagai jantung kehidupan ekoonomi, politik, sosial, budaya, dan pertahanan keamanan Seperti halnya jasa trasportasi gojek. Gojek merupakan pencetus ojek daring terbesar di Indonesia dan bernaung di bawah perusahaan PT Gojek Indonesia. Gojek menggunakan teknologi aplikasi berbasis androit. Aplikasi gojek dapat di unduh di semartphone baik itu androit maupun IOS. Cara kerjanya gojek ialah menggunakan aplikasi yang memanfaatkan media elektronik dan harus tersambung dengan internet. Para custemer tidak usah menanti lama dan menunggu di jalan-jalan atau menghampiri ke terminal ojek, gojek akan menjemput anda dan mengantarkannya sampai pada tempat tujuan.

Perusahaan yang meyediakan trasportasi berbasis online tersebut mempunyai lebih dari 20 fitur dan layanan, seperti GoRide, GoCar, GoBluebird, melayani pengangkutan penumpang, GoSend melayani pengiriman barang, GoFood melayani pengambilan barang, GoMart melayani pemesanan barang di toko seperti Inomaret, toserba dan sejenisnya, GoTix, GoPay, GoGames melayani pemesanan tiket konser, berita, dan sejeninsnya, GoBox membantu penyaluran barang dengan sekala besar, GoClea membantu pembersihan rumah, kantor, atau apartemen, GoMassage, GoFitnes membantu pemijatan atau olah raga, GoPulsa, GoNearby, GoBills, GoPoints, GoGive, Golnvestasi melayani pembayaran, GoShop melayani pembelanjaan di Supermarket, GoMed/Haloodoc melayani beli obat di apotek terdekat. Pada saat ini, gojek sudah beroperasi di seluruh kota/kabupaten di Indonesia dengan 2,5 juta lebih pengendara ojek online.

Kehadiran gojek sangat membantu bagi perekonomian masyarakat. Mereka yang bekerja menjadi driver gojek memiliki penghasilan tambahan. Tak ada tatanan yang mewajibkan bekerja min 7-8 jam dan 6-7 hari bekerja dalam seminggu. Hal inilah yang membentuk driver gojek dapat disortir menjadi 2 kalangan, yaitu: drver gojek fulltime dan driver gojek parttime. Driver gojek fulltime biasanya mulai bekerja dari pagi pukul 06:00 pagi hingga pukul 22:00 malam. Bisanya istirahat dari pukul 10:00 pagi sampai pukul 12:00 siang dan pukul 14:00 sampai pukul 15:00 sore, karena pukul istirahat tersebut biasanya orderan sepi. Sedangkan driver gojek parttime biasanya bekerja 4-5 jam. Biasanya mulai mencari orderan setelah mereka bekerja.

Upah setiap hari dari driver gojek banyak berdampak oleh berbagai hal selayak: banyaknya orderan, kurun tempuh, lamanya operasi, bonus, tips/imbalan, dan beban yang disalurkan tiap harinya. Pendapatan driver gojek menggunakan sistem bagi hasil antara driver gojek dengan perseroan. Pemenggalan hasil dapat dihitung selayaknya berikut, 80\% teruntuk driver, 20\% untuk perusahaan. Upah driver gojek selama sebulan mungkin bisa dapat diatas UMR, terkhusus UMR yang berjalan di kota Surabaya sebesar Rp 4.200.479. banyaknya Upah di kota Surabaya diketahui berdasarkan keputusan Gubernur Jatim.

Rumusan masalah dari pengkajian ini ialah apakah upah driver gojek fulltime upah di atas atau di bawah Upah Minimal daerah kota Surabaya. bertujuan dari pengkajian ini ialah untuk menilik upah driver gojek fulltime melebihi atau kurang dari Upah Minimal daerah kota Surabaya. 


\section{TELAAH PUSTAKA}

\section{Upah}

Menurut Tri Siwi Agustina (2015) Upah ialah pemberian yang diberikan perusahaan sebagai balas jasa atas hasil kerja yang diberikan oleh tenaga kerja. imbalan dari pemberi kerja. Upah ditetapkan dan dibayarkan sesuai kesepakatan kerja, kesepakatan, atau aturan pemerintah, terbilang tunjangan bagi buruh atas suatu pekerjaan dan atau jasa yang telah dilakukan.

\section{Pendapatan}

Pendapatan ialah alat yang bisa untuk menghitung kemakmura rakyat, sehingga pendapatan rakyat ini mencerminkan kekuatan ekonomi suatu masyarakat.

Upah adalah semua penghasilan yang diperoleh oleh pekerja baik dari bagian formal ataupun tidak formal yang dijumlah dalam kurun waktu yang ditentukan

Kementrian Perhubungan (kemenhub) mengumumkan tarif ojek online naik Rp 250,00 per kilometer mulai tanggal 1 Agustus 2019. Berdasarkan keputusan Mentri Perhubungan RI Nomor Kp 384 Tahun 2019 tentang tarif ojek online, untuk zona satu terdiri dari Sumatera, Bali, Jawa selain Jabodetabek. Dari per kilometer Rp 1.600,00 menjadi Rp 1.850,00. Batas minimal untuk perjalanan kurang dari empat kilometer naik dari 8 ribu berubah menjadi 10 ribu. Skema tarif ojek online dibagi menjadi tiga zona, sesuai Kementrian Perhubungan RI Nomor KP 348 Tahun 2019. Pendapatan driver gojek, akan langsung terlihat otomatis ketika konsumen sudah memesan di aplikasi dan menentukan lokasi lokasi tujuan, tarif gojek ditentukan berdasarkan jarak tempuh yang di tuju. Semakin banyak permintaan atau semakin jauh tujuannya maka semakin banyak pula hasil pendapatan yang di terimanya. Pemenggalan sistem bagi hasil sebanyak $80 \%$ teruntuk driver gojek dan $20 \%$ untuk perseroan.

Gojek juga memberikan poin dan bonus agar driver gojek lebih semangat dalam bekerja. Poin dan bonus berlaku 1×24 jam, mulai pukul 00:00 sampai 23:59. Poin untuk GoRide satu sedangkan poin untuk GoFood, GoMart, GoSend, dan GoShop satu koma lima. Bonus diberikan apabila mencapai poin yang sudah ditentukan. Berikut perhitungan poin dan bonus driver gojek.

Tabel 1.1 poin dan bonus driver gojek

\begin{tabular}{|c|l|}
\hline Poin & \multicolumn{1}{|c|}{ Bonus } \\
\hline 6 & $\mathrm{Rp} 6.000$ \\
\hline 10 & $\mathrm{Rp} 6.000$ \\
\hline 13 & $\mathrm{Rp} 3.000$ \\
\hline 17 & $\mathrm{Rp} 25.000$ \\
\hline 21 & $\mathrm{Rp} 30.000$ \\
\hline 25 & $\mathrm{Rp} 20.000$ \\
\hline 30 & $\mathrm{Rp} 40.000$ \\
\hline Jumlah Bonus & $\mathrm{Rp} 130.000$ \\
\hline \multicolumn{2}{|c|}{ Sumber: aplikasi diver gojek }
\end{tabular}

\section{Teori Jam Kerja}

Buruh adalah rakyat yang bersedia beraktivitas, dan yang nganggur lamun bersedia dan menyanganggup beraktivitas dan mereka yang tidak bekerja akibat tidak tersedia lowongan kerja

Menjadi driver gojek tidak diikat oleh waktu jam kerja, mereka bisa beraktivitas kapanpun dan di manapun. Sehingga seorang driver bisa mengatur jamya sendiri untuk bekerja. Tidak terikat aturan yang mengharuskan bekerja sedikitnya 7 sampai 8 jam dan 6 sampai 7 hari kerja seminggu, hal itu yang menjadikan driver gojek dapat dibagi menjadi 2 kalangan, yaitu: driver gojek fulltime dan driver gojek parttime. Driver gojek fulltime mulai bekerja dari pagi pukul 06:00 hingga pukul 22:00 
malam. Biasanya driver gojek fulltime istirahat pukul 10:00 sampai pukul 12:00 siang dan pukul 14:00 samapi pukul 15:00 sore, karena jam-jam istirahat itu biasanya orderan sepi. Sedangkan driver gojek parttime biasanya bekerja 4-5 jam. Biasanya driver gojek parttime mulai mencari orderan setelah mereka bekerja

\section{METODE PENELITIAN \\ Subyek dan Obyek Penenlitian}

Subyek dalam penelitian ini ialah 50 driver gojek fulltime dengan kriterian yang berstatus masih aktif, sudah bekerja minimal 1 tahun, dan bekerja di Kota Surabaya. Sedangkan obyek penelitian ini adalah pendapatan driver gojek fulltime sejumlah 50 driver di Kota Surabaya.

\section{Kerangka Konseptual}

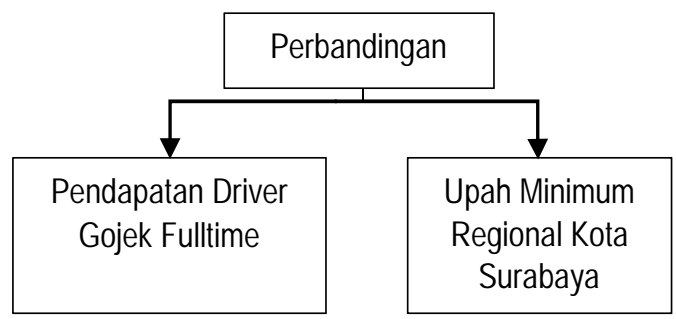

Gambar 1.1 kerangka konseptual

Gambar di atas menjelaskan tentang pedapatan driver gojek fulltime ada melebihi atau kurang dari besarnya UMR Kota Surabaya. Penelitian ini membandingkan pendapatan sebulan driver gojek fulltime dengan UMR kota Surabaya. UMR yang berguna di kota Surabaya sebesar Rp 4.200.479,00. Besarnya UMR di kota Surabaya diketahui berdasarkan keputusan Gubernur Jatim,.

\section{Teknik Pengumpulan Data}

1. Observasi

Dalam proses penghimpunan data teknik yang dimanfaatkan dalam pengkajian ini yaitu:

Metode pengamatan yang diadopsi dalam pengkajian ini ialah teknik pengamatan partisipatif. Dalam pengamatan ini penulis ikut terlibat bekerja sehari-hari dengan orang yang sedang diamati atau yang digunakan sebagai sumber penelitian (Sugiyono, 2019)

2. Wawancara

Penulis menggunakan wawancara terstruktu, wawancara ini digunakan sebagai teknik pengumpulan data, apabila penulis atau pengumpul data telah mengetahui dengan pasti tentang info apa saja yang diperoleh (Sugiyono, 2019)

3. Dokumentasi

Menurut Sugiyono (2019) dokumentasi adalah catatan peristiwa yang sudah berlalu. Dokumentasi bisa berbentuk tulisan, gambar, atau karya-karya monumental dari seseorang. Dalam penelitian ini dokumentasi yang didapat berupa foto hasil wawancara seperti pendapatan, bonus dan poin driver gojek fulltime di kota Surabaya.

\section{Validitas Data}

Validitas ialah ukuran kecakapan antara informasi yang terjadi pada bahan pengkajian dengan informasi yang bisa dipertanggung jawabkan oleh pengkaji. Dengan begitu informasi yang valit yaitu informasi yang tidak berbeda antara informasi yang disajikan dengan informasi yang sebenarnya berlangsung pada fokus penegkajian. (Sugiyono, 2019).

Untuk mendapat kevalidtan data penulis mengadopsi metode triangulasi.

Pada pengkajian ini pengkaji mengadopsi tes validitas data triangulasi sumber, triangulasi metode, dan triangulasi waktu.

\section{Teknik Analisa Data}


Teknik yang diadopsi dalam pengkajian ini menggunakan metode analisis deskriptif komparatif. Metode ini dilakukan untuk membandingkan pendapatan driver gojek fulltime dengan Upah Minimum Regional Kota Surabaya.

Langkah-langkah yang dimanfaatkan dalam menjawab rumusan masalah pengkajian ini yaitu sebagai berikut:

1. Mendiskripsikan UMR Kota Surabaya

Tahun 2020 UMR kota Surabaya sangat tinggi, yaitu sebanyak 4 juta duaratus ribu. angka berikut menjadi UMR terbesar di Jawa Timur. Sesuai dengan judul yang diteliti, UMR kota Surabaya menjadi informasi penelitian dalam keterkaitan dengan banyaknya upah driver gojek fulltime kota Surabaya.

2. Menghitung Pendapatan Driver Gojek Fulltime

Penulis melakukan observasi dan wawancara secara ter struktur. Dalam menjalankan wawancara, penulis sudah menyiapkan perbincangan tertulis dan jawabannya. Setiap driver diberi arahan dan di training dahulu, agar bisa menjawab pertanyaan-pertanyaan yang di ajukan oleh penulis.

3. Membandingkan Pendapatan Driver Gojek Fulltime Dengan UMR Kota Surabaya

Berikut rancangan tabel yang akan mengetahui berapa banyak pendapatan driver gojek fulltime yang di atas atau di bawah UMR kota Surabaya.

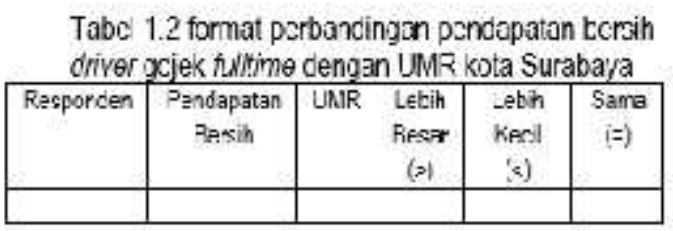

Tabel di atas merupakan format perbandingan pendapatan bersih driver gojek fulltime dengan UMR kota Surabaya. Pendapatan bersih tersebut dimasukkan ke dalam tabel dan di samakan dengan UMR kota Surabaya. Jika pendapatan driver gojek fulltime lebih kecil dari UMR, maka diberi simbol $\leq$ dan jika pendapatan driver gojek fulltime lebih besar dari UMR maka diberi simbol $\geq$ dan jika pendapatan driver gojek fulltime sama dengan UMR maka diberi simbol $=$.

\section{HASIL PENELITIAN DAN PEMBAHASAN}

Informasi yang didapat dari medan jumlahnya begitu banyak, olehkarena itu perlu dituis dengan teliti dan rinci.informasi yang akan di reduksi dalam kajian ini adalah hasil dari pengamatani, Tanya jawab, dan dokumentasi lalu diolah dan memfokuskan semua data mentah agar lebih bermakna.

Selanjutnya penulis menggunakan informasi primer dan informasi skunder. Berikut hasil data primer dan data sekunder yang didapat:

\section{A. Data Skunder}

1. Sejarah Gojek

Gojek ialah layanan penyaji jasa angkutan berbasis online yang awal terbentuk di bandung. Perseroan yang didbuat oleh Nadiem Makarim, Kevin Aluwi dan Michaelangelo Moran pada bulan Oktober 2010.

Pada saat ini, lebih dari 2,5 juta driver gojek dan sudah beroperasi di 167 Kabupaten/Kota di seluruh Indonesia. Pada tanggal 22 juli 2019, gojek merilis ikon baru dan metode pencatatan korporasi terbaru. lambang barunya yang disebut "Solv" mencitrakan perubahan gojek menjadi pelayanan ojek daring berubah aplikasi hebat yang menyajikan banyak metode cemerlang untuk mengurangi kesulitan. Sedangkan merek gojek yang bermula disebut GOJEK diubah menjadi gojek tanpa ada kata penghubung. lambang terbaru yang disebut Solv ini dijabarkan menggunakan bulatan yang tidak presisi dengan titik dibagian tengah. Nama Solv dikutip dari kata "Solve" yang berarti menyelesaikan. Gojek berasa, ini sempurna 
dengan misi mereka, yaitu menjadi "aplikasi hebat" yang dapat memberi berbagai masalah pelanggan.

2. Visi Misi Gojek

Visi gojek ialah mempermudah jajaran angkutan di Indonesia menyajikan kemudahan untuk rakyat dalam menjalankan pekerjaan tiap hari layaknya penyaluran barang, membeli dengan memanfaatkan layanan media kurir, bisa juga memakmurkan kehidupan gojek di Indonesia. Misi gojek ialah menjadi tolak ukur jalannya kedisplinan dan cara kerja jajaran angkutan yang layak dengan memanfaatkan pertumbuhan teknologi. Menyuguhkan layanan bagus dan jalan keluar yang bernilai untuk pelanggan dan membuka lapangan pekerjaan rakyat nusantara.

3. Jenis Jenis Layanan Gojek

Gojek mempunyai 20 fitur terhitung dari angkutan, membeli dan mengantar makanan, beli, antar paket, pembayaran, pijat, sampai membersihkan rumah dan kendaraan karena gojek adalah ragam solusi untuk setiap situasi. Berikut layanan-layanan yang ada di aplikasi gojek: GoRide, GoFood, GoSend, GoMart, GoShop, GoCar, GoBluebird, GoTix, GoPlay, GoGames, GoBox, GoClean, GoMassage, GoFitness, GoPulsa, GoBils, GoPoints, GoGive, Golnvestasi, GoMed.

\section{B. Data Primer}

maksud eksplorasi data primer yang digunakan yaitu hasil pendapatan yang didapat dari wawancara dan observasi. Pendapatan bersih tersebut akan dibedakan dengan Upah Minimum Regional kota Surabaya yang dapat dilihat pada tabel di bawah ini:

Tabel 1.3 perbandingan pendapatan bersih driver gojek fulltime dengan UMR kota Surabaya

\begin{tabular}{|c|c|c|c|c|c|}
\hline Responden & \begin{tabular}{c} 
Pendapatan \\
\cline { 3 - 6 }
\end{tabular} & $\begin{array}{c}\text { Uersih (Rp) } \\
\text { Kota } \\
\text { Surabaya } \\
(\mathrm{Rp})\end{array}$ & $\begin{array}{c}\text { Lesar }(\geq) \\
(\mathrm{Rp})\end{array}$ & $\begin{array}{c}\text { Kecil }(\leq) \\
(\mathrm{Rp})\end{array}$ & $\begin{array}{c}\text { Sama } \\
(=)\end{array}$ \\
\hline 1 & 2.985 .000 & 4.200 .000 & - & 1.215 .000 & - \\
\hline 2 & 2.985 .000 & 4.200 .000 & - & 1.215 .000 & - \\
\hline 3 & 2.985 .000 & 4.200 .000 & - & 1.215 .000 & - \\
\hline 4 & 2.985 .000 & 4.200 .000 & - & 1.215 .000 & - \\
\hline 5 & 3.885 .000 & 4.200 .000 & - & 315.000 & - \\
\hline 6 & 3.885 .000 & 4.200 .000 & - & 315.000 & - \\
\hline 7 & 3.885 .000 & 4.200 .000 & - & 315.000 & - \\
\hline 8 & 4.932 .000 & 4.200 .000 & 732.000 & - & - \\
\hline 9 & 4.932 .000 & 4.200 .000 & 732.000 & - & - \\
\hline 10 & 4.932 .000 & 4.200 .000 & 732.000 & - & - \\
\hline 11 & 5.325 .000 & 4.200 .000 & 1.125 .000 & - & - \\
\hline 12 & 5.325 .000 & 4.200 .000 & 1.125 .000 & - & - \\
\hline 13 & 6.525 .000 & 4.200 .000 & 2.325 .000 & - & - \\
\hline 14 & 6.525 .000 & 4.200 .000 & 2.325 .000 & - & - \\
\hline 15 & 6.525 .000 & 4.200 .000 & 2.325 .000 & - & - \\
\hline 16 & 6.525 .000 & 4.200 .000 & 2.325 .000 & - & - \\
\hline 17 & 6.525 .000 & 4.200 .000 & 2.325 .000 & - & - \\
\hline 18 & 6.075 .000 & 4.200 .000 & 1.875 .000 & - & - \\
\hline 19 & 7.275 .000 & 4.200 .000 & 3.075 .000 & - & - \\
\hline 20 & 7.275 .000 & 4.200 .000 & 3.075 .000 & - & - \\
\hline 21 & 7.275 .000 & 4.200 .000 & 3.075 .000 & - & - \\
\hline 22 & 7.275 .000 & 4.200 .000 & 3.075 .000 & & - \\
\hline 23 & 7.275 .000 & 4.200 .000 & 3.075 .000 & - & - \\
\hline 24 & 7.275 .000 & 4.200 .000 & 3.075 .000 & - & - \\
\hline 25 & 7.275 .000 & 4.200 .000 & 3.075 .000 & - & - \\
\hline 26 & 7.275 .000 & 4.200 .000 & 3.075 .000 & - & - \\
\hline 27 & 7.275 .000 & 4.200 .000 & 3.075 .000 & - & - \\
\hline 28 & 7.275 .000 & 4.200 .000 & 3.075 .000 & - & - \\
\hline 29 & 7.275 .000 & 4.200 .000 & 3.075 .000 & - & - \\
\hline & & & & & \\
\hline
\end{tabular}




\begin{tabular}{|c|c|c|c|c|c|}
\hline 30 & 8.475 .000 & 4.200 .000 & 4.275 .000 & - & - \\
\hline 31 & 8.475 .000 & 4.200 .000 & 4.275 .000 & - & - \\
\hline 32 & 8.475 .000 & 4.200 .000 & 4.275 .000 & - & - \\
\hline 33 & 8.475 .000 & 4.200 .000 & 4.275 .000 & - & - \\
\hline 34 & 8.775 .000 & 4.200 .000 & 4.575 .000 & - & - \\
\hline 35 & 8.775 .000 & 4.200 .000 & 4.575 .000 & - & - \\
\hline 36 & 9.825 .000 & 4.200 .000 & 5.625 .000 & - & - \\
\hline 37 & 9.825 .000 & 4.200 .000 & 5.625 .000 & - & - \\
\hline 38 & 9.825 .000 & 4.200 .000 & 5.625 .000 & - & - \\
\hline 39 & 10.725 .000 & 4.200 .000 & 6.525 .000 & - & - \\
\hline 40 & 10.725 .000 & 4.200 .000 & 6.525 .000 & - & - \\
\hline 41 & 10.725 .000 & 4.200 .000 & 6.525 .000 & - & - \\
\hline 42 & 11.175 .000 & 4.200 .000 & 6.525 .000 & - & - \\
\hline 43 & 11.175 .000 & 4.200 .000 & 6.525 .000 & - & - \\
\hline 44 & 11.175 .000 & 4.200 .000 & 6.525 .000 & - & - \\
\hline 45 & 11.175 .000 & 4.200 .000 & 6.525 .000 & - & - \\
\hline 46 & 11.175 .000 & 4.200 .000 & 6.525 .000 & - & - \\
\hline 47 & 11.175 .000 & 4.200 .000 & 6.525 .000 & - & - \\
\hline 48 & 11.175 .000 & 4.200 .000 & 6.525 .000 & - & - \\
\hline 49 & 11.175 .000 & 4.200 .000 & 6.525 .000 & - & - \\
\hline 50 & 11.175 .000 & 4.200 .000 & 6.525 .000 & - & - \\
\hline
\end{tabular}

\section{Dokumentasi}

Pada penelitian ini data dokumentasi yang didapat berupa foto-foto hasil wawancara, seperti pendapatan bonus dan poin driver gojek fulltime yang bisa dilihat pada gambar di bawah ini:

\section{Poin dan Bonus Gojek}

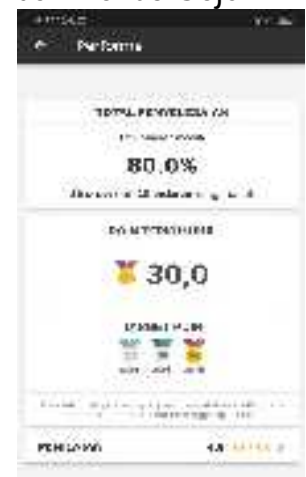

Gambar 1.2 poin dan bonus driver gojek

2. Pendapatan Per Hari Driver Gojek

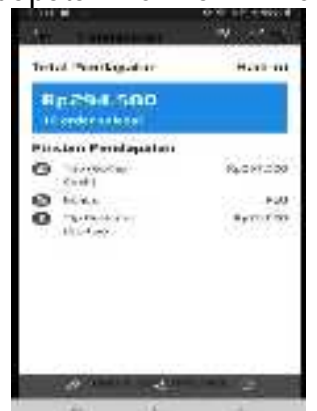

Gambar 1.3 pendapatan per hari driver gojek

Gambar di atas adalah hasil penelitian dari wawancara dan dokumentasi dimana penulis memintak screnshoot hasil pendapatan, bonus dan poin kepada driver gojek fulltime di kota Surabaya. 
Berdasarkan hasil tabel 1.3 dapat dilihat bahwa pendapatan driver gojek fulltime lebih banyak di atas UMR dari pada di bawahnya, dan untuk lebih rinci bisa dilihat pada grafik di bawah ini:

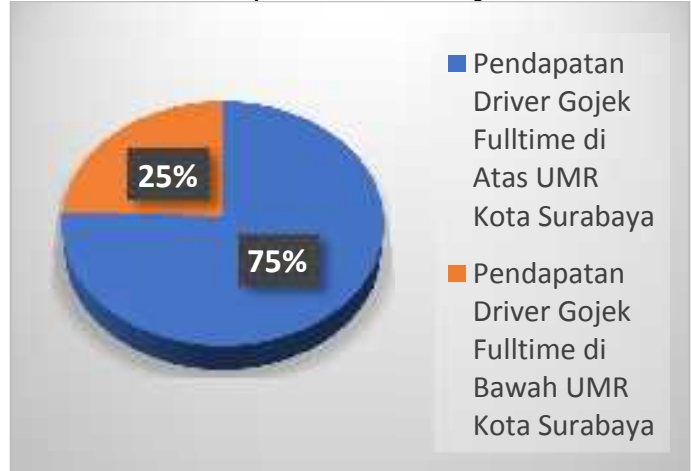

Grafik 1.1 perbandingan pendapatan driver gojek fulltime

Pada grafik di atas dapat disimpul-kan bahwa sebanyak $75 \%$ driver gojek fulltime pendapatannya berada di atas UMR kota Surabaya dan $25 \%$ driver gojek fulltime pendapatannya berada di bawah UMR kota Surabaya.

\section{SIMPULAN}

Belandaskan hasil investigasi dan pejabaran di atas, dapat ditarik kesimpulan bahwa pendapatan sebulan yang diterima oleh driver gojek fulltime sebanyak $75 \%$ pendapatannya berada di atas UMR kota Surabaya dan 25\% pendapatannya berada di bawah UMR kota Surabaya. Sistem pembagian hasil yang diterima sebesar delapan puluh persen untuk driver dan dua puluh persen untuk perusahaan sudah menguntungkan bagi para gojek. Pendapatan terendah sebulan yang diterima oleh driver gojek sebesar Rp 2.985.000 dan pendapatan tertinggi sebulan yang diterima oleh driver gojek sebesar Rp 11.175.000. Pendapatan per hari seorang driver gojek bisa berubah ubah tergantung hasil orderan yang diperoleh, bonus yang di dapat dan jarak order yang di tempuh. Semakin jauh jarak yang di tempuh maka semakin banyak pula ongkos/pendapatan yang diterima. 